\title{
STUDY OF THE PHYSICOCHEMICAL AND COMMERCIAL PROPERTIES OF NPK FERTILIZERS
}

\author{
Tursunov Shahboz \\ Master of the Karshi Engineering and Economic Institute \\ Panjiev Olimjon \\ Associate Professor of the Karshi Engineering and Economic Institute, \\ olimjon573_@mail.ru
}

\begin{abstract}
Kyzylkum phosphate rock was studied with a nitric acid content of 50 and 75 and $100 \%$, as well as in fertilizers obtained from the ratio of $\mathrm{R} 2 \mathrm{O} 5$ : $\mathrm{K} 2 \mathrm{O}=1: 1$. The gyroscopic points of the fertilizer size of 2-3 mm were determined at $250^{\circ} \mathrm{C}$ by the desiccator method of N.Ye. Pestov. The points of hygroscopicity of fertilizer samples with an initial moisture content of $1.0 \%$ were No. 1 46.5\%, No. 2 - $38.0 \%$ and No. 3 - 32.4\%.
\end{abstract} sorption.

Keywords: phosphorite, nitric acid, desiccant method, hygroscopicity, NPK fertilizer,

\section{INTRODUCTION}

The physicochemical and commercial properties of fertilizer grains (hygroscopicity, moisture capacity, viscosity, strength) were studied on the next enriched Kyzylkum phosphate rock with a nitric acid content of 50, 75 and $100 \%$ and a ratio of $\mathrm{R} 2 \mathrm{O} 5: \mathrm{K} 2 \mathrm{O}=1: 1$. The gyroscopic points of the size of $2-3 \mathrm{~mm}$ of the fertilizer were determined at $250^{\circ} \mathrm{C}$ using the desiccator method by N.Ye. Pestov[1]. The points of hygroscopicity of fertilizer samples with an initial moisture content of $1.0 \%$ were No. $1-46.5 \%$, No. $2-38.0 \%$, and No. $3-32.4 \%$. It is known that the hygroscopicity of a fertilizer largely depends on the moisture content in it, the presence of water-soluble salts, and so on. We have determined the effect of moisture on their hygroscopicity (table 1.).

Table 1.

Dependence of the point of hygroscopicity on the moisture content of NPK fertilizer

\begin{tabular}{|c|c|c|c|c|c|c|}
\hline \multirow{2}{*}{$\begin{array}{c}\text { Sequential number } \\
\text { of NPK fertilizer }\end{array}$} & \multicolumn{5}{|c|}{ Moisture-dependent hygroscopicity of NPK fertilizers, \% } \\
\cline { 2 - 7 } samples & 1,0 & 2,0 & 3,0 & 4,0 & 5,0 & 6,0 \\
\hline 1 & 46,5 & 54,2 & 61,1 & 66,3 & 71,0 & 72,9 \\
\hline 2 & 38,0 & 47,5 & 54,1 & 60,8 & 63,9 & 66,1 \\
\hline 3 & 32,4 & 31,6 & 48,0 & 54,1 & 59,2 & 62 \\
\hline
\end{tabular}

Table 1 shows the increase in hygroscopic points with increasing moisture in NPK fertilizer 
samples. Based on the values of the hygroscopicity of NPK fertilizers obtained at 50, 75 and 100\% of the stoichiometric norm of HNO3, it was found that they belong to hygroscopic substances. However, these values correspond to the actual humidity of the air in the atmosphere, and there is no rapid transition from wet to dry. This, in turn, prevents the saturated solution of salts from settling under the film and reduces the adhesive properties of the fertilizer grains. Due to the value of the hygroscopic points, these fertilizers are always wet, therefore we recommend storing them in 4-layer plastic bags.

It should be noted that the points of hygroscopicity of products determine the necessary conditions for their storage, transportation and use. However, the hygroscopicity of fertilizers is not considered the only indicator that allows them to be applied. Also, moisture capacity and other factors are of great importance.

The sorption capacity of the obtained fertilizers with a size of 2-3 $\mathrm{mm}$ was determined by the method of M.E. Pestov at a temperature of $250{ }^{\circ} \mathrm{C}$ and air humidity from 10 to $100 \%$ [2]. The sorption of water vapor was relatively high due to the presence of a thin layer of product and the close proximity of the interval between sulfuric acid of a certain concentration. The sorption process starts at a relative humidity of $15-20 \%$, depending on the type of fertilizer and the hygroscopic point in the graph shown.

At a relative humidity of $100 \%$, the balance was not established even for a month. Kinetics of vapor sorption of NPK fertilizers - minimum and maximum values of the average relative humidity 41; 61 and $80 \%$ (in the conditions of Central Asia). At a relative humidity of $41 \%$, equilibrium was reached after 7 days, in $61 \%$ after 9 days and in $80 \%$ after 13 days. The high moisture content of fertilizers is explained by the presence of water-soluble salts in them: calcium, magnesium nitrate, ammonia, magnesium monophosphate, ammonium nitrate and others.

The viscosity is determined by the method of N.E. Pestova, the maximum value of the average relative humidity per month is $80 \%$, fertilizer with a grain size of $3>01>1 \mathrm{~mm}$ is poured into gauze bags, pressed for 24 hours under load. on special equipment.

After a day, the bags were dried to constant weight at $1050^{\circ} \mathrm{C}$ without removal, then dropped from a height of $1.5 \mathrm{~m}$ and passed through a sieve with a diameter of $3 \mathrm{~mm}$. The relative viscosity was determined depending on the initial moisture content and load. Nitrophosphate fertilizers with an initial moisture content of 1.5 and $3 \%$ do not stick in practice.

This is explained by the fact that the hygroscopicity of the proposed fertilizers lies in areas where the relative humidity of the air is lower than the relative humidity of the atmosphere. Consequently, the transition from the wetting process to the drying process does not occur when fertilizers are stored under conditions of real changes in the humidity of the air atmosphere. This prevents the precipitation of salt crystals, which cement the products and are due to their viscosity, from the saturated solution.

The strength of NPK-fertilizer grains was determined on a spring scale by the НИУИФ method [2]. The measurements were carried out on 20 samples with a size of 2-3 mm. The average grain strength was 3.4-3.7 MПа. For all selected samples, the static strength value must be at least 2 МПа, in accordance with the requirements of the state all-union standard 95.11-77, applied to complex phosphorus-containing fertilizers. 


\section{List of used literature:}

1. Methods of nitric acid processing of phosphate raw materials into complex fertilizers. // Overview of sulfur mineral fertilizers and sulfuric acid. НИИТЭХИМ.- М .: 1977.- 47 p.

2. Reimov A.M. Development of technology for obtaining nitrocalcium phosphate nitrocalcium sulfophosphate fertilizers on the basis of decomposition of Kyzylkum phosphorites at a reduced rate of nitric acid: Abstract of the dissertation of the candidate of technical sciences.Tashkent, 2004.-23 p.

3. Resolution of the Cabinet of Ministers of the Republic of Uzbekistan No. 219 dated May 16, 2001 "On the integrated development of the Kyzyl Kum phosphorites".

4. Mikheev V.I. Radiometric determinant of minerals. In 2 volumes - M .: 1957.T.1.-868 p.

5. Topor N.D., Ogorodova L.P., Melchakova L.V. Thermal analysis of minerals and inorganic compounds. M .: Moscow State University. 1987.-270 p. 